\title{
Direct, extended, and mass-mediated contact with immigrants in Italy: their associations with emotions, prejudice, and humanity perceptions
}

\author{
Emilio Paolo Visintin ${ }^{1}$, Alberto Voci ${ }^{2}$, Lisa Pagotto ${ }^{2}$, Miles Hewstone ${ }^{3}$ \\ ${ }^{1}$ Institute of Psychology, University of Lausanne, and Department of Philosophy, Sociology, Education and Applied Psychology, University of \\ Padova \\ ${ }^{2}$ Department of Philosophy, Sociology, Education and Applied Psychology, University of Padova \\ ${ }^{3}$ Department of Experimental Psychology, University of Oxford
}

\author{
Correspondence concerning this article should \\ be addressed to Emilio Paolo Visintin, Institute \\ of Psychology, University of Lausanne, \\ Bâtiment Géopolis, Lausanne CH-1015, \\ Switzerland. \\ E-mail: emiliop.visintin@gmail.com; \\ emiliopaolo.visintin@unil.ch
}

doi: 10.1111/jasp. 12423

\begin{abstract}
Two correlational studies investigated the associations between different forms of intergroup contact, on the one hand, and Italians' prejudice and humanity attributions toward immigrants in Italy, on the other. Study 1 examined the effects of direct contact, extended contact, and parasocial contact through mass-media, assessing separately contact through TV news and newspapers and contact through entertainment programs. Study 2 analyzed the distinct effects of positive and negative episodes of the contact forms considered in Study 1. Across the studies, we tested the mediational role of intergroup anxiety, empathy, and trust. Overall, results showed the importance of taking into account different forms of contact and considering the emotional processes during contact experiences to understand intergroup attitudes.
\end{abstract}

\section{Introduction}

In his seminal book, Allport (1954) introduced the most influential statement of the contact hypothesis: Interactions between people belonging to different groups under optimal conditions (i.e., equal status within the contact situation, common goals and intergroup cooperation, and institutional support) can reduce prejudice. The contact hypothesis has received considerable attention and inspired a great number of studies that tested its effectiveness and extended its basic principles (Brown \& Hewstone, 2005; Pettigrew \& Tropp, 2006). Robust support for the contact hypothesis was provided by Pettigrew and Tropp's (2006) meta-analysis of 515 studies, which yielded a significant negative correlation between contact and prejudice. The meta-analysis further showed that Allport's optimal conditions facilitate prejudice reduction, but are not essential for the effectiveness of contact.

Despite the clarity of the findings obtained so far, some aspects of intergroup contact still deserve further investigation. First of all, although direct contact is effective in reducing prejudice, this strategy is sometimes difficult to promote and implement. Indeed, where opportunities for contact are rare, it is difficult to create positive intergroup encounters (Dixon, Durrheim, \& Tredoux, 2005). Moreover, even in multicultural societies where contact is possible, people may not easily develop friendships or intimate relationships with outgroup members. In these contexts, indirect forms of contact, that do not necessarily imply face-to-face interactions, may be implemented (Dovidio, Eller, \& Hewstone, 2011). For instance, extended contact-the knowledge that an ingroup member has an outgroup friend (Wright, Aron, McLaughlin-Volpe, \& Ropp, 1997) — has proved to yield beneficial effects in many segregated contexts (e.g., Christ et al., 2010). Additionally, when people have limited direct knowledge of outgroup members, contact through mass media, and specifically the portrayal of outgroup members and intergroup interactions conveyed by newspaper, TV news, and entertainment programs, may represent an important source of information about outgroups and influence intergroup attitudes (Mutz \& Goldman, 2010). The simultaneous investigation of different forms of intergroup contact, including, direct, extended, and mass-mediated contact is thus of particular interest.

Second, to fully understand the dynamics of intergroup relations, it is important to distinguish between intergroup 
experiences perceived as positive and intergroup experiences perceived as negative, that may differentially shape intergroup attitudes. Indeed, although research on negative contact is limited, there is now growing evidence that this type of contact influences negatively intergroup perceptions and may hinder or counteract the beneficial effects of positive contact (Barlow et al., 2012; Pettigrew, 2008).

Third, it is essential to understand through which mechanisms intergroup contact exerts its effects. Research over the last decade has devoted considerable attention to the study of possible mediators, and empirical findings indicate that affective factors such as intergroup anxiety, empathy, and trust play a crucial role (Brown \& Hewstone, 2005; Pettigrew \& Tropp, 2008). Although the simultaneous analysis of multiple mediators has characterized recent research (e.g., Swart, Hewstone, Christ, \& Voci, 2011), this topic needs further investigation, in particular when considering different types of intergroup contact as predictors and different intergroup perceptions as outcomes.

A final, important issue to address to unravel the complexity of intergroup contexts is to estimate intergroup perceptions and attitudes accurately. Given that overt expression of hostility and explicit discrimination are nowadays socially disapproved and normatively sanctioned (Dovidio \& Gaertner, 2004), it is also necessary to consider additional outcomes to blatant prejudice. Here we focused on infrahumanization, that is, the perception of outgroup members as less human than ingroup members (Leyens, Demoulin, Vaes, Gaunt, \& Paladino, 2007).

Therefore, in the present studies we aimed to investigate the effects of different forms of contact on prejudice and on perceptions of the outgroup's humanity. Specifically, we considered direct contact, extended contact and parasocial contact through mass-media, furthermore distinguishing between contact through TV news and newspapers, on the one hand, and contact through entertainment programs, on the other. Moreover, we intended to disentangle the independent role of positive and negative episodes of these forms of contact. Additionally, we tested the mediational role of affective variables, namely empathy and trust toward the outgroup, and intergroup anxiety.

Our research was conducted in Italy, and analyzed the intergroup context of Italians and immigrants, considering the point of view of Italian respondents. Immigration in Italy is a relatively recent phenomenon that began in the 1970s in response to the increase of economic wealth and industrialization. In line with the argument that recency of immigration is associated with negative attitudes and discrimination against foreigners (e.g., Pettigrew, 1998), social surveys have demonstrated that anti-immigrant feelings are stronger in Italy than in other European countries (Eurobarometer, 2008), and that Italians feel threatened by the presence of immigrants, who are considered to be too numerous and linked to criminality (Italian National Institute of Statistics, 2012).

\section{Indirect forms of contact}

When opportunities for face-to-face intergroup encounters are scarce, indirect forms of contact may play a crucial role in affecting intergroup attitudes (Dovidio et al., 2011). The extended contact hypothesis (Wright et al., 1997) proposed that knowing ingroup members who have outgroup friends can ameliorate attitudes toward the outgroup as a whole. Compared with direct contact, extended contact has some advantages: Observing an intergroup interaction should be less likely to induce anxiety elicited in real encounters, and a single cross-group friendship may be observed by many persons, so it is not necessary for each individual to engage in direct contact with members of the other group (see Turner, Hewstone, Voci, Paolini, \& Christ, 2007; for a comprehensive review, see Vezzali, Hewstone, Capozza, Giovannini, \& Wölfer, 2014). Research has widely demonstrated the beneficial effects of extended contact in ameliorating intergroup relations (Turner, Hewstone, Voci, Paolini, et al., 2007; Vezzali et al., 2014, for a meta-analysis, see Zhou, Page-Gould, Aron, Moyer, \& Hewstone, 2016), especially in segregated contexts (e.g., Andrighetto, Mari, Volpato, \& Behluli, 2012) and when direct contact is rare (Christ et al., 2010; Eller, Abrams, \& Gomez, 2012).

In Italy, where both our studies were carried out, direct contact between Italians and immigrants is possible but Italian society is characterized by a certain degree of segregation concerning work places (e.g., Fullin \& Reyneri, 2011) and areas of cities where the two communities live (e.g., Mudu, 2006). Thus, extended contact might play a crucial role in prejudice reduction.

Besides direct and extended contact, which imply the existence of a real cross-group interaction, there are even more indirect forms of contact that do not involve real encounters but impact intergroup perceptions and evaluations. As outlined in the review by Mutz and Goldman (2010), massmedia represent an important source of information about outgroups, especially for people who have limited direct knowledge of outgroup members. The exposure to mass media leads to shifts in prejudice levels in both positive and negative directions, depending on the valence of the portrayal of outgroups (Graves, 1999; Mutz \& Goldman, 2010). Regardless of evidence showing the beneficial effects of positive vicarious contact for prejudice reduction (Lienemann, \& Stopp, 2013; Mazziotta, Mummendey, \& Wright, 2011; Ortiz \& Harwood, 2007; Schiappa, Gregg, \& Hewes, 2005; Shim, Zhang, \& Harwood, 2012), the actual content of mass mediated communication may not always provide a positive image of outgroups, especially of racial outgroups.

Importantly, research in this field suggests that we should distinguish between exposure to news media and exposure to 
entertainment media (Armstrong \& Neuendorf, 1992; Pagotto, Voci, \& Maculan, 2010; Sotirovic, 2001), as they may have different effects on prejudicial beliefs. For example, Armstrong and Neuendorf (1992) demonstrated in the American context that among White respondents exposure to TV news was associated with negative evaluation of the socio-economic standing of Blacks, while exposure to entertainment media was related to a more positive evaluation.

Although research has shown that both face-to-face and mass-mediated contact can impact intergroup attitudes, there is limited research investigating these forms of contact simultaneously. For example Ramasubramanian (2013) found that White Americans who considered family, friends and acquaintances as the main information source about Blacks reported less stereotypical perceptions and less prejudice compared with those who used television, films, magazines, and newspapers as primary source of information about Blacks.

It is well-known that media depictions of immigrants are typically negative (e.g., Boomgaarden \& Vliegenthart, 2009; Brader, Valentino, \& Suhay, 2008; ter Wal, d'Haenens, \& Koeman, 2005). In Italy the media devote great attention to immigration, and racist ideas are spread by television news and newspapers, which often convey a link between immigration, criminality, and insecurity (Baussano, 2012; Vaes, Latrofa, Vieno, \& Pastore, 2015). Moreover, TV news and newspapers over-represent the percentage of illegal, compared with legal, immigrants (Monzini, 2005). In contrast, immigration and immigrants are increasingly portrayed in a positive light in Italian films and TV series (O'Healy, 2010). In entertainment broadcasts, immigrants' point of view is usually presented in a personalized way, leading the viewer to identify with characters' life circumstances and events. Thus, the distinction between news media and entertainment media (Armstrong \& Neuendorf, 1992) appears crucial when considering the portrayals of immigrants in Italy.

To recap, the influences of extended contact and of the portrayal of outgroups in mass-mediated communication on prejudice are established. However, research has not yet tested simultaneously the effects of direct contact, extended contact, and parasocial contact through mass media on prejudice and on humanity perceptions. Here, we sought to test simultaneously the effects of these forms of contact, to disentangle their independent roles on prejudice and on humanity attributions toward immigrants in Italy.

\section{Positive and negative intergroup contact}

Recently, some scholars have pointed out the scarcity of research on negative experiences of contact (Pettigrew, 2008; Pettigrew \& Tropp, 2006). As already acknowledged by Allport (1954) in his early formulation of the contact hypothesis, intergroup contact in natural settings is not always positive, and negative episodes of contact may even worsen prejudice. Scholars have recently acknowledged the importance of considering negative contact experiences. Aberson (2015), for example, found that positive and negative contact have independent effects, the former being related to lower threat perceptions and prejudice, and the latter being associated with more threat and prejudice. Research has also tried to compare the strength of effects of positive and negative contact. Findings however are mixed: While some studies found that the effects of negative contact are stronger than the effects of positive contact (Aberson, 2015; Barlow et al., 2012; Graf, Paolini, \& Rubin, 2014), other studies found the opposite pattern (Pettigrew, 2008) and others did not find reliable differences in the magnitude of the effects of positive and negative contact (Bekhuis, Ruiter, \& Coenders, 2013).

The distinction between positive and negative contact experiences should also be applied to indirect forms of contact. In this vein, Mazziotta, Rohmann, Wright, TezanosPinto, and Lutterbach (2015) found that positive and negative extended contact are independent predictors of prejudice, and, further, that they favor or inhibit positive and negative direct contact. Differentiating between positive and negative contact also appears necessary when considering mass-mediated contact. Indeed, the content of massmediated information about outgroup members is often mixed and includes contrasting information that might convey a different and complex portrayal of outgroups.

In sum, research has demonstrated that positive and negative direct contact are two distinct phenomena. However, there is only limited research analyzing the distinction between positive and negative episodes of indirect types of contact (Labianca, Brass, \& Gray, 1998; Mazziotta et al., 2015; Pagotto \& Voci, 2013). In our second study, we aimed at extending previous research by examining how positive and negative direct and indirect contact differently impact prejudice and humanity attributions to the outgroup.

\section{Mediating mechanisms of the relationship between contact and prejudice}

Since the formulation of the intergroup contact hypothesis, researchers have striven to understand how contact works, and have identified a number of cognitive and affective processes that underlie the beneficial effects of contact, i.e., the mediating mechanisms.

The first mediator was proposed by Allport (1954), who believed that contact was effective due to new information about the outgroup that people could gain, and the subsequent change of stereotypical beliefs. Although this cognitive mechanism has proved to exert some effects on reducing 
prejudice (e.g., Eller \& Abrams, 2004), there is now general agreement that affective factors play a greater role in the contact process than cognitive factors do (Brown \& Hewstone, 2005; Miller, Smith, \& Mackie, 2004). Empirical evidence and meta-analytic findings by Pettigrew and Tropp (2008) clearly support this claim.

In the investigation of affect-based processes in contact experiences, scholars have first focused on negative emotions and feelings, and in particular on the anxiety-reduction mechanism. Intergroup anxiety refers to feelings of uneasiness experienced by a person when expecting negative consequences for the self during interactions with outgroup members (Stephan, 2014; Stephan \& Stephan, 1985). Empirical evidence has shown that positive contact experiences typically alleviate feelings of anxiety and threat, which in turn are associated with decreased prejudice (e.g., Swart et al., 2011; Turner, Hewstone, \& Voci, 2007).

With regard to positive affective mediators, increased empathy has been indicated as one of the most important variables involved in contact experiences. Batson (1991) defined empathy as an affective state that stems from and is congruent with the perceived welfare of another. A growing body of research has shown that intergroup contact, especially when positive and intimate, is associated with enhanced empathy for outgroup members, which in turn relates to more positive outgroup attitudes (e.g., Swart et al., 2011; Turner, Tam, Hewstone, Kenworthy, \& Cairns, 2013).

Besides these two affective mediators, outgroup trust has been recently proposed as a possible mediating mechanism between contact and reduced prejudice (Čehajić, Brown, \& Castano, 2008; Kenworthy et al., 2016; Tam, Hewstone, Kenworthy, \& Cairns, 2009). Trust, defined as positive expectations about the behavior of the other party (Lewicki, McAllister, \& Bies, 1998), is associated with feelings of transparency and confidence in the other's intentions. Although trust between members of different groups is difficult to establish, repeated and positive encounters can effectively contribute to its development and, once formed, it can promote cooperation and benevolence (Kramer \& Carnevale, 2001). Indeed, research has shown that trust in the outgroup mediated the effects of direct contact on forgiveness (Čehajić et al., 2008) and behavioral tendencies (Kenworthy et al., 2016; Tam et al., 2009). Given that outgroup trust is characterized by positive expectations and complex feelings toward outgroup members, it should have a prominent role in favoring the attribution of human characteristics to the outgroup, such as secondary emotions and uniquely human traits.

While the mediational roles of negative emotions such as intergroup anxiety and of positive effects such as empathy and trust toward the outgroup are well-established with respect to the effects of direct contact, their role in the relationship between indirect intergroup contact and prejudice needs to be further addressed. Concerning extended contact, there is some evidence that extended contact, similarly to direct contact, reduces intergroup anxiety (e.g., Mereish, \& Poteat, 2015; Paolini, Hewstone, Cairns, \& Voci, 2004) and increases outgroup trust (e.g., Visintin, Brylka, Green, Mähönen, \& Jasinskaja-Lahti, 2016) and empathy (Turner et al., 2013; Visintin et al., 2016). For mass-mediated contact, the parasocial contact hypothesis (Schiappa et al., 2005) suggested that people process media experiences similarly to direct experiences: Thus, contact through the mass media may change emotional reactions toward the outgroup in the same way that direct contact does. Indeed, research has shown that the portrayal of outgroups in mass-mediated programs may impact intergroup anxiety (Ortiz \& Harwood, 2007; Shim et al., 2012), empathic feelings (Paluck, 2009), and outgroup trust (Pagotto \& Voci, 2013).

In this paper we sought to further investigate the involvement of affective, emotional processes in the relationship between various forms of indirect contact and prejudice and humanity perceptions, besides the initial evidence reported above. Our proposition, based on the reviewed literature, is that direct and extended contact, as well as the portrayal of outgroup members in mass-media, are associated with affective, emotional reactions toward outgroup members, and that these emotions are in turn associated with outgroup prejudice and humanity.

\section{Prejudice and humanity bias}

In contemporary societies many forms of blatant prejudice and discrimination are no longer socially acceptable, but may have been replaced by more subtle and indirect prejudice expressions (Dovidio \& Gaertner, 2004). Thus, while people may avoid manifesting blatant negative feelings or stereotypes and behaving in an overtly discriminatory fashion, they may still have subtle prejudice and negative intergroup perceptions. We thus also considered, besides blatant prejudice, infrahumanization, that is, the attribution of more uniquely human characteristics to the ingroup than to the outgroup (for reviews, see Leyens et al., 2007; Vaes, Leyens, Paladino, \& Pires Miranda, 2012). This so-called humanity bias can be expressed through the belief that the ingroup experiences more secondary, uniquely human emotions than the outgroup (e.g., Leyens et al., 2001), or through the attribution of more uniquely human traits or characteristics to the ingroup than to the outgroup (e.g., MacInnis \& Hodson, 2012). Infrahumanization is particularly dangerous because considering the outgroup as not fully human leads to moral disengagement (Bandura, 1999) and reduces helping behaviors (Cuddy, Rock, \& Norton, 2007). Research on intergroup contact has, however, demonstrated that intergroup contact may reduce infrahumanization (e.g., Brown, Eller, Leeds, \& Stace, 2007; Capozza, Falvo, Di Bernardo, Vezzali, \& Visintin, 2014), and there is some initial evidence that extended 
contact may also have similar effects (e.g., Andrighetto et al., 2012).

In our studies, with the aim of accurately assessing intergroup perceptions, we hence investigated both blatant prejudice and the humanity bias.

\section{Overview of the studies}

In two studies, we investigated the effects of three different forms of contact, namely direct, extended, and massmediated, on outgroup prejudice and on outgroup humanity attributions. For mass-mediated parasocial contact, we examined separately contact through television news and newspapers and contact through films, situation comedies, and TV series. In the second study, we analyzed the distinct effects of positive and negative episodes of direct contact, extended contact, contact through television news and newspapers, and contact through films.

Across the two studies, we investigated possible mediators of the relationships between the forms of contact and intergroup attitudes. We focused on the more prominent affective processes (see Pettigrew \& Tropp, 2008) by considering the two most reliable mediators, namely intergroup anxiety and empathy toward the outgroup, and a more recently proposed mediator, i.e., outgroup trust.

\section{Study 1}

In Study 1, we hypothesized that the different forms of contact under examination would have independent effects on intergroup attitudes. Direct contact and extended contact should be related negatively to prejudice and positively to outgroup humanization; these effects should be mediated by emotions, namely empathy and trust toward the outgroup, and intergroup anxiety. Given the portrayal of immigrants in Italian mass-media, we expected contact through TV news to be particularly negative, and thus related to increased anxiety and prejudice and reduced positive emotions, while contact through films and TV series should be associated with reduced prejudice and to the perception of the outgroup as human.

\section{Method}

\section{Participants and procedure}

Participants were 199 Italians, aged between 15 and 84 $\left(M_{\text {age }}=30.76, S D=13.58\right) ; 84$ were males, and 115 females. They completed the questionnaire individually and were recruited through the social network of two research collaborators.

\section{Measures in the questionnaire}

Predictors. Direct contact was measured by three items that tapped both quantitative and qualitative facets of intergroup contact: "How many immigrants in Italy do you know personally?", "How many immigrants in Italy do you know well?", and "How many immigrants are friends of yours?" (adapted from Voci \& Hewstone, 2003). The response scale ranged from 0 (none) to 4 ( $a$ lot). A reliable composite index was created by averaging the three items $(\alpha=.81)$. Extended contact was measured with a single item, adapted from Turner, Hewstone, and Voci (2007). Participants were asked to report "How many of the Italian people you know have friends who are immigrants?" on a scale ranging from 0 (none) to 4 ( $a$ lot). To assess quantity of mass-mediated parasocial contact, two items were used (adapted from Pagotto et al., 2010): one item referred to contact through TV news and newspaper ("How often do you hear news about immigrants, e.g., in TV news, newspapers, on the radio?") and the other to contact through films and TV series ("How often do you see immigrants in films, TV series?"). For both items, response scale ranged from 0 (never) to 4 (very often).

Affective mediators. Empathy toward the outgroup was measured with items adapted from Voci and Hewstone (2007). Participants were asked to think about discrimination and difficulties experienced by immigrants living in Italy, and to rate 12 emotional reactions (e.g., sorrow, emotional closeness) on a scale from 0 (not at all) to 4 (very much). A reliable composite score was computed by averaging the twelve items $(\alpha=.95)$. To measure intergroup anxiety, we adapted Stephan and Stephan's (1985) scale. Participants were asked to imagine being the only Italian, in Italy, among unknown immigrants of their own gender, and to rate on a scale from 0 (not at all) to 4 (very $m u c h$ ) four emotional reactions (e.g., calm [reverse coded], embarrassed). Items were averaged to form a reliable composite score $(\alpha=.76)$. To assess outgroup trust, participants were asked how often they experienced three trust-related emotions (trust, positive expectations, feeling of trustworthiness) toward immigrants in Italy (Voci, 2006). Responses ranged from 0 (never) to 4 (very often). Items were averaged to form a reliable composite index $(\alpha=.88)$.

Criterion variables. Prejudice was assessed by asking participants to describe, on a scale from 0 (not at all) to 4 (very much), their attitude toward immigrants using four adjectives (e.g., positive [reverse coded], unfavorable) (Pagotto \& Voci, 2013). We created a reliable composite index by averaging the four items $(\alpha=.89)$. To measure humanity perceptions of the ingroup and of the outgroup, we used a scale developed by Capozza, Trifiletti, Vezzali, and Favara (2013). Participants were asked to rate how much 
Table 1 Descriptive Statistics and Correlations Between Variables (Study 1)

\begin{tabular}{|c|c|c|c|c|c|c|c|c|c|}
\hline & 1 & 2 & 3 & 4 & 5 & 6 & 7 & 8 & 9 \\
\hline 1. Direct contact & - & & & & & & & & \\
\hline 2. Extended contact & $.35^{* * *}$ & - & & & & & & & \\
\hline 3. Contact-TV news and newspapers & -.02 & $.16^{*}$ & - & & & & & & \\
\hline 4. Contact-Films and TV series & .08 & $.22 * *$ & $.14^{*}$ & - & & & & & \\
\hline 5. Empathy & $.25^{* \star *}$ & $.16^{*}$ & -.07 & -.02 & - & & & & \\
\hline 6. Anxiety & $-.19 * *$ & -.09 & $.20 * *$ & -.12 & $-.28 * * *$ & - & & & \\
\hline 7. Trust & $.29 * * *$ & $.26 * * *$ & -.04 & .04 & $.64^{* * *}$ & $-.37 * * *$ & - & & \\
\hline 8. Outgroup prejudice & $-.35 * * *$ & $-.31 * * *$ & .12 & -.03 & $-.73 * * *$ & $.41 * * *$ & $-.73 * * *$ & - & \\
\hline 9. Outgroup humanity & $.27 * * *$ & $.28 * * *$ & -.09 & $.18^{*}$ & $.41 * \star *$ & $-.30 * * *$ & $.44 * * *$ & $-.44^{* * *}$ & - \\
\hline Mean & 1.02 & 1.25 & 3.04 & 1.77 & 1.87 & 2.32 & 1.56 & 1.59 & 4.13 \\
\hline Standard Deviation & 0.67 & 0.74 & 0.76 & 0.90 & 0.93 & 0.70 & 0.78 & 0.82 & 1.00 \\
\hline
\end{tabular}

Note. ${ }^{*} p<.05 .{ }^{*} p<.01 .{ }^{* * *} p \leq .001$.

immigrants and Italians are characterized by eight traits, on a scale ranging from 1 (absolutely false) to 7 (absolutely true). Four traits (e.g., reasoning, morality) were uniquely human traits, so they could be attributed only to humans and not to animals; four traits (e.g., impulsiveness, drive) were nonuniquely human traits, so they could be attributed to humans and to animals. Items were averaged to form two composite indexes for immigrants $(\alpha=.79$ for uniquely human traits, and .78 for non-uniquely human traits) and two composite indexes for Italians $(\alpha=.82$ for uniquely human traits, and .79 for non-uniquely human traits).

\section{Results and discussion}

\section{Preliminary analyses}

Descriptive statistics and correlations between variables are reported in Table 1. Both direct and extended contact with immigrants were rather infrequent. Contact through TV news and newspapers was more frequent, while contact through films and TV series was not very frequent. As regards intergroup emotions, participants expressed moderate levels of intergroup anxiety, low levels of trust, and intermediate levels of empathy toward immigrants. Participants reported quite low levels of prejudice toward immigrants.

Concerning humanity perceptions, we computed a 2 (Target group: immigrants vs. Italians) $\times 2$ (Traits: uniquely human vs. non-uniquely human traits) repeated-measures analysis of variance. We found a main effect of target group, $F(1,198)=12.74, p<.001, \eta_{\mathrm{p}}^{2}=.06$ : Participants attributed more traits in general to Italians $(M=4.63, S D=0.74)$ than to immigrants $(M=4.42, S D=0.78)$. We also found a main effect of traits, $F(1,198)=49.44, p<.001, \eta_{\mathrm{p}}^{2}=.20$ : Attributions of non-uniquely human traits were generally higher $(M=4.72, \quad S D=0.76)$ than attributions of uniquely human traits $(M=4.33, S D=0.74)$. More interestingly, we found a significant Target group $\times$ Traits interaction, $F(1,198)=9.88, p=.002, \eta_{\mathrm{p}}^{2}=.05$. Uniquely human traits were attributed more to Italians $(M=4.53, S D=1.01)$ than to immigrants $(M=4.13, S D=1.00), F(1,198)=18.02$, $p<.001, \eta_{\mathrm{p}}^{2}=.08$, indicating an effect of infrahumanization of the outgroup (Leyens et al., 2007). Non-uniquely human traits were attributed equally to Italians $(M=4.72$, $S D=0.85)$ and immigrants $(M=4.72, S D=0.99), F<1$. Finally, participants attributed more non-uniquely human traits (vs. uniquely human traits) both to Italians and to immigrants, $F \mathrm{~s}(1,198) \geq 5.71, p s<.018, \eta_{\mathrm{p}}^{2} \mathrm{~s} \geq .03$. The greater attribution of non-uniquely human traits (vs. uniquely human traits) to both groups could reflect the cultural stereotype toward these groups, who are considered more warm and impulsive than rational (Durante, 2008).

With the aim of testing convergent and discriminant validity of the constructs, we applied Confirmatory Factor Analysis (CFA) using Mplus 6 (Muthén \& Muthén, 2010) to the constructs measured by multiple items included in the regression models. As variables were measured by several items, to smooth measurement error and keep an adequate ratio of cases to parameters, we applied the partial disaggregation approach (Bagozzi \& Heatherton, 1994). For each variable we created two indicators by averaging subsets of items. A good fit of the model to the data is indicated by a non-significant chi-square or by a ratio between chi square and degrees of freedom lower than 2, a root mean square error of approximation (RMSEA) lower than .06, a standardized root mean square residual (SRMR) lower than .08, and a comparative fit index (CFI) higher than .95 (Hooper, Coughlan, \& Mullen, 2008). The model fitted the data well, $\chi^{2}(39)=56.77$, $p=.033, \chi^{2} /$ df ratio $=1.45$, RMSEA $=.048$, SRMR $=.024$, $\mathrm{CFI}=0.99$. All parcel loadings were significant $(p s<.001)$ and higher than .55 , showing convergent validity. Furthermore, all the latent variables were distinct constructs, with $\Phi$ coefficients all different from $|1.00|$ (95\% confidence interval), providing evidence for discriminant validity.

\section{Path model}

To assess the hypothesized relationships between variables, we tested a path model with observed variables 
(Mplus 6) where direct contact, extended contact, parasocial contact through TV news and newspapers, and parasocial contact through films and TV series were the predictors; empathy, anxiety, and trust were the mediators; prejudice and outgroup humanization were the outcome variables. Direct paths from the predictors to the outcome variables were estimated, as well as correlations between the predictors, between the mediators and between the outcome variables.

Direct contact was positively associated with empathy and with trust, and negatively with intergroup anxiety (see Table 2). Extended contact was positively associated with trust, while contact through TV news and newspapers was positively associated with intergroup anxiety. Turning to the relationships between the mediators and the outcome variables, both empathy and trust were negatively associated with prejudice and positively associated with outgroup humanization. Intergroup anxiety was positively associated with prejudice. Moreover, some significant direct effects were also present: Extended contact was negatively associated with prejudice and positively with outgroup humanization while contact through films and TV series was positively associated with outgroup humanization. All the other estimated regression coefficients were non-significant ( $p s \geq .066$ ) (see also Figure 1). ${ }^{1}$

Mediation analyses. To test the significance of indirect effects, we applied bootstrapping procedures using 10,000 resamples (Preacher \& Hayes, 2008). A 95\% confidence interval $(\mathrm{CI})$ that excludes zero indicates a significant mediation with $p<.05$. A $95 \% \mathrm{CI}$ with one of the limits equal to zero indicates mediation is significant with $p=.05$. As shown in Table 3, direct contact was associated with reduced prejudice through empathy, anxiety, and trust, and was positively associated with outgroup humanity through empathy and trust. Extended contact was associated negatively with prejudice and positively with outgroup humanity through trust, while contact through TV news and newspapers was related to more prejudice through anxiety. Last, contact through films and TV series had a negative indirect effect on prejudice via anxiety $(p=.05){ }^{2}$

To summarize, direct contact was negatively associated with prejudice through the mediation of the three intergroup emotions and positively to outgroup humanity via trust and empathy. The other forms of contact also had reliable effects. Extended contact was negatively related

\footnotetext{
${ }^{1}$ The results were almost identical when including gender and age as control variables, in this Study as well as in Study 2.

${ }^{2}$ It is worth acknowledging that the indirect effects of parasocial contact through TV news and newspapers, and of parasocial contact through films and TV series, via anxiety on prejudice emerged even if the bivariate correlations of these forms of contact and prejudice were not significant (see Table 1).
}
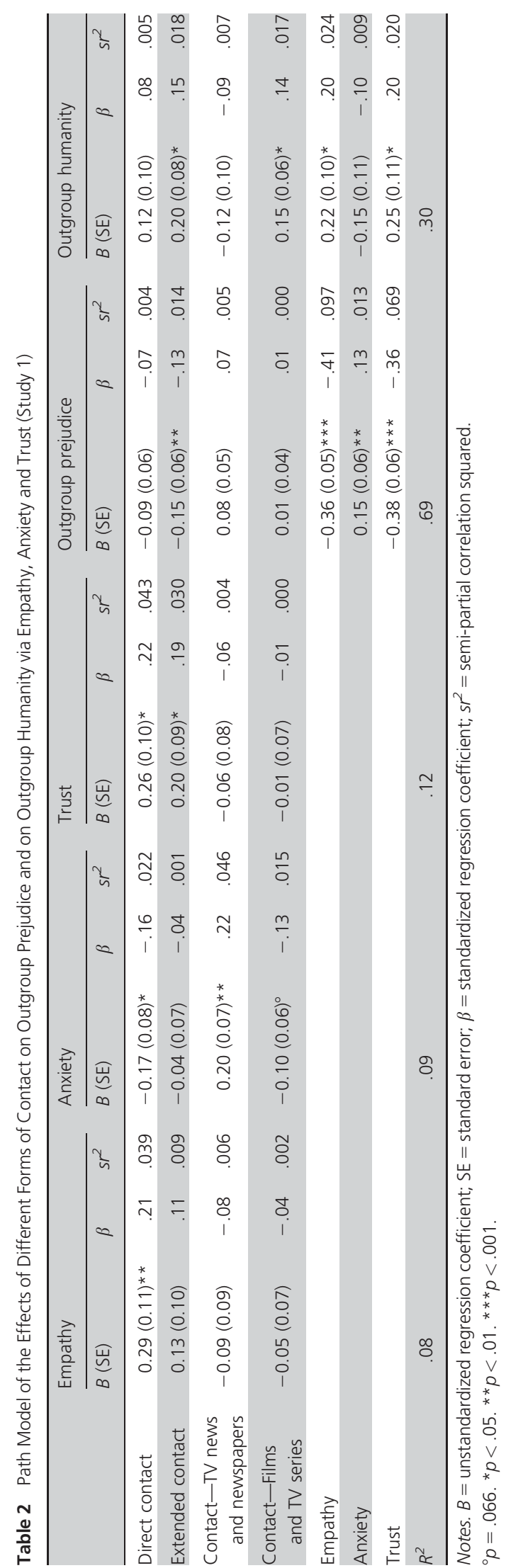

Journal of Applied Social Psychology, 2017, 47, pp. 175-194 


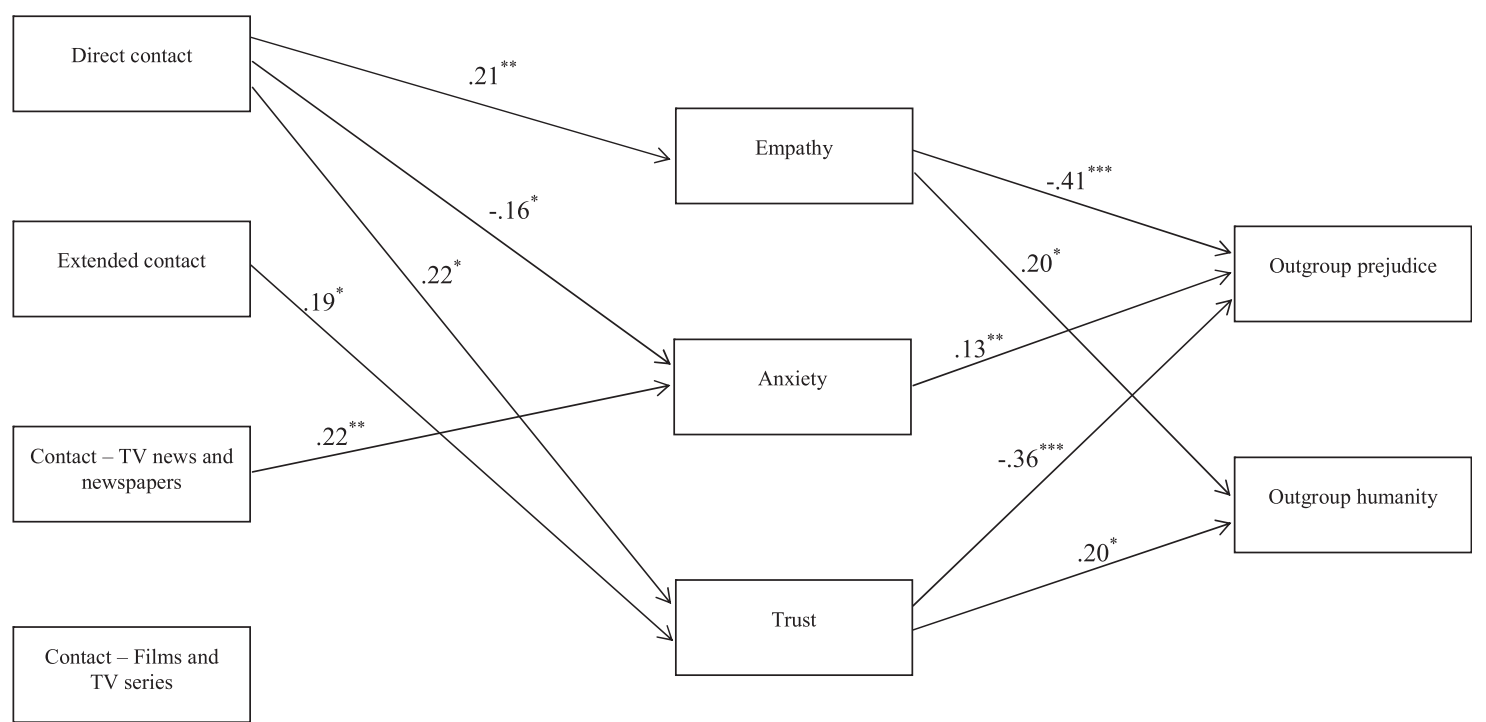

Figure 1 Indirect effects of different forms of contact on outgroup prejudice and on outgroup humanity via empathy, anxiety and trust (Study 1). Standardized coefficients are reported. Only significant paths are reported. Direct effects of contact variables on outgroup prejudice and on outgroup humanity are not displayed (for direct effects see Table 2). ${ }^{*} p<.05 .{ }^{* *} p<.01 .{ }^{* * *} p<.001$.

to prejudice and positively to outgroup humanity, and these effects occurred partially via outgroup trust. In contrast, parasocial contact through TV news and newspapers was positively associated with prejudice, partially due to its positive association with intergroup anxiety. Finally, parasocial contact through films and TV series was related to the perception of the outgroup as human and to reduced prejudice.

\section{Study 2}

Study 1 suggested that indirect contact might be positively or negatively associated with prejudice and that the nature of the association between indirect contact and prejudice depends on the form of contact. To unravel why parasocial contact through TV news and newspapers was associated with more prejudice while the other forms of contact were

Table 3 Unstandardized Total and Indirect Effects, and Bootstrap Point Estimates and [95\% Bootstrap Confidence Intervals] of the Effects of Different Forms of Intergroup Contact on Criterion Variables via Intergroup Emotions (Study 1)

\begin{tabular}{|c|c|c|}
\hline Mediators & Outgroup prejudice & Outgroup humanity \\
\hline Direct contact & $\mathrm{TE}=-0.32 * * *, \mathrm{IE}=-0.23^{* *}$ & $\mathrm{TE}=0.27^{* *}, \mathrm{IE}=0.15^{*}$ \\
\hline Empathy & $-0.11[-\mathbf{0 . 1 9 7},-\mathbf{0 . 0 3 2}]$ & $0.06[0.010,0.173]$ \\
\hline Intergroup anxiety & $-0.02[-\mathbf{0 . 0 6 4},-\mathbf{0 . 0 0 3}]$ & $0.02[-0.005,0.090]$ \\
\hline Trust & $-0.10[-0.191,-0.024]$ & $0.06[0.009, \mathbf{0 . 1 7 1}]$ \\
\hline Extended contact & $\mathrm{TE}=-0.28^{* * *}, \mathrm{IE}=-0.13^{\circ}$ & $\mathrm{TE}=0.29 * * *, \mathrm{IE}=0.09^{\circ}$ \\
\hline Empathy & $-0.05[-0.122,0.022]$ & $0.03[-0.007,0.104]$ \\
\hline Intergroup anxiety & $-0.01[-0.034,0.014]$ & $0.01[-0.011,0.051]$ \\
\hline Trust & $-0.08[-0.156,-0.014]$ & $0.05[0.004,0.144]$ \\
\hline Contact-TV news and newspapers & $\mathrm{TE}=0.16^{*}, \mathrm{IE}=0.09$ & $\mathrm{TE}=-0.19^{\circ}, \mathrm{IE}=-0.07$ \\
\hline Empathy & $0.03[-0.026,0.100]$ & $-0.02[-0.079,0.011]$ \\
\hline Intergroup anxiety & $0.03[0.006, \mathbf{0} .071]$ & $-0.03[-0.102,0.008]$ \\
\hline Trust & $0.02[-0.034,0.093]$ & $-0.02[-0.090,0.018]$ \\
\hline Contact_-Films and TV series & $\mathrm{TE}=0.02, \mathrm{IE}=0.01$ & $\mathrm{TE}=0.15^{*}, \mathrm{IE}=0.00$ \\
\hline Empathy & $0.02[-0.034,0.075]$ & $-0.01[-0.053,0.019]$ \\
\hline Intergroup anxiety & $-0.02[-\mathbf{0 . 0 4 3}, \mathbf{0 . 0 0 0}]$ & $0.02[-0.003,0.063]$ \\
\hline Trust & $0.00[-0.048,0.055]$ & $0.00[-0.047,0.033]$ \\
\hline
\end{tabular}

Notes. TE $=$ Total Effect of predictor on criterion variable; IE $=$ Indirect effect of predictor on criterion variable.

${ }^{\circ} p<.10 .{ }^{*} p<.05 .{ }^{* *} p<.01 .{ }^{* *} p \leq .001$.

Bootstrap Confidence intervals ( $\mathrm{Cls}$ ) excluding zero indicate a significant indirect effect $(p<.05)$. Bootstrap Cls with one of the limits equal to zero indicate an indirect effect significant at $p=.05$. These $\mathrm{Cls}$ are in bold. 
associated with more positive outgroup attitudes, in Study 2 we distinguished the effects of positive and negative experiences of the four previously considered forms of contact.

Considering findings from other intergroup contexts (e.g., Barlow et al., 2012; Brylka, Jasinskaja-Lahti, \& Mähönen, 2016; Graf et al., 2014; Pettigrew, 2008) we expected participants to report more frequent positive direct than negative direct contact. The same should be true for extended contact, based on the observation of direct interactions. It should be noted that positive extended contact, i.e. observing positive cross-group encounters, is conceptually close to the more general construct of extended contact, i.e. observing or knowing about a cross-group friendship, that is, a positive relationship, but specifically refers only to the observation of episodes that are clearly considered pleasant and generating positive mood and emotions. As suggested by Study 1, however, contact through TV news and newspapers should be mainly negative, thus respondents should report frequent negative contact through TV news, and rare positive contact through TV news. Finally, participants should report positive impressions of immigrants seen in films and TV series more frequently than negative impressions.

We hypothesized that positive and negative episodes of each form of contact would have independent effects on intergroup emotions and intergroup attitudes. In general, for each of the considered forms of contact, positive episodes should be related to lower prejudice and to more attributions of uniquely human characteristics to the outgroup, while negative contact should be associated with negative outgroup perceptions, i.e., more prejudice and lower outgroup humanization. As in Study 1, we tested whether the effects of positive and negative forms of contact were mediated by intergroup emotions.

\section{Method}

\section{Participants and procedure}

Participants were 330 Italians (155 males and 175 females), aged between 16 and $77\left(M_{\mathrm{age}}=29.70, S D=13.01\right)$, who agreed to take part in the study when approached. As in Study 1, participants completed the questionnaire individually; they were recruited through the social network of three research collaborators.

\section{Measures in the questionnaire}

Predictors. Positive and negative direct contact were measured by two items each (Pagotto \& Voci, 2013). The questions were "How often do you interact with the immigrants you know and perceive the experience as positive [negative]?", and "How often, meeting the immigrants you know, do you feel comfortable [discomfort]?." The response scales ranged from 0 to $4(0=$ never, $1=$ rarely, $2=$ sometimes, $3=$ often, $4=$ very often). The two items for positive direct contact and the two items for negative direct contact were averaged to create reliable composite scores (SpearmanBrown reliability statistic for a two-item measure: $\rho=.88$ for positive direct contact, $\rho=.82$ for negative direct contact).

Two items were used to measure positive and negative extended contact: "How often do you observe the relationship between Italians you know and immigrants, and judge the relationship as positive [negative]?", and "How often do you observe the relationship between Italians you know and immigrants, and feel comfortable [discomfort]?." Responses ranged from 0 (never) to 4 (very often). The two items of positive extended contact and the two items of negative extended contact were averaged to form reliable indexes $(\rho=.92$ for positive extended contact, $\rho=.85$ for negative extended contact)..$^{3}$

Positive and negative parasocial contact through mass-media were measured by single items, separately for contact through TV news and newspapers, and contact through films and TV series (Pagotto \& Voci, 2013), with the following items: "How often do you get a positive [negative] impression of immigrants you hear about on TV news, radio news, newspapers?" and "How often do you get a positive [negative] impression of immigrants you see in films and TV series?". Response scales ranged from 0 (never) to 4 (very often).

Affective mediators. For outgroup empathy and outgroup trust, we used the same scales as Study 1. The two scales were reliable $(\alpha=.93$, and $\alpha=.85$, respectively). For intergroup anxiety, we used the same introductory question as Study 1 and six items (e.g., calm [reverse coded)], anxious; $0=$ not at all, $4=$ very much; $\alpha=.89$ ).

Criterion variables. Criterion variables were the same as Study 1. Alphas ranged from .80 to .88 .

\section{Results and discussion}

\section{Preliminary analyses}

Descriptive statistics and correlations between variables are reported in Table 4. Consistent with our expectations, positive direct contact with immigrants was quite frequent, while negative direct contact was less frequent, and the two scores

\footnotetext{
${ }^{3}$ For both direct and extended contact, the first items assessed the frequency of positive and negative contacts, while the second items assessed the feelings experienced during positive and negative contacts. We calculated bivariate correlations between the direct and extended contact single items and intergroup anxiety, to ensure that the items assessing feelings experienced during positive and negative encounters do not empirically overlap with anxiety. The highest absolute value of correlations was .31, confirming that the contact items are empirically distinct from anxiety.
} 


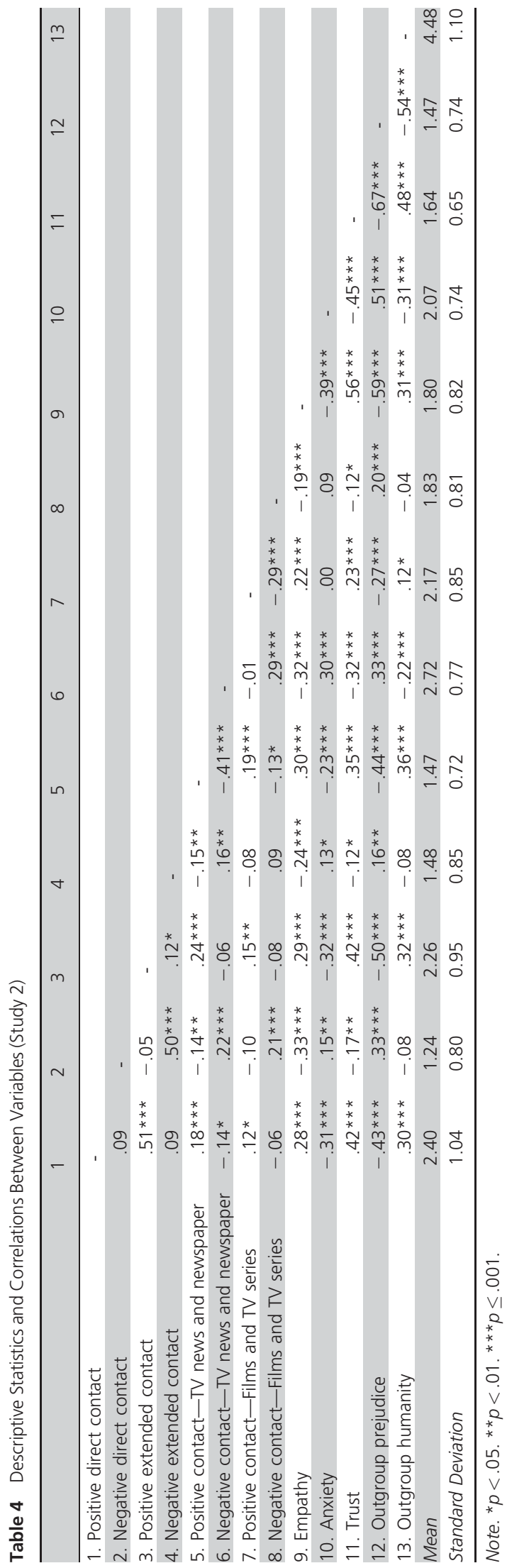

were significantly different, $t(329)=16.68, p<.001$. Results were similar with regard to extended contact: Participants reported observing positive interactions between Italians and immigrants more frequently than negative interactions, $t(329)=11.77, p<.001$. As expected, results concerning contact through TV news and newspapers were in the opposite direction: Respondents received a negative image of immigrants from TV news and newspapers more frequently than a positive image, $t(329)=18.29, p<.001$. As regards contact through films and TV series, participants received a positive impression of immigrants more frequently than a negative impression, $t(329)=4.55, p<.001$.

Concerning intergroup emotions, respondents reported medium levels of intergroup anxiety, did not empathize much with immigrants' suffering, and did not trust immigrants much. As in Study 1, however, participants reported quite low prejudice toward immigrants.

Humanity attribution scores were submitted to a 2 (Target group: immigrants vs. Italians) $\times 2$ (Traits: uniquely human vs. non-uniquely human traits) repeated-measures ANOVA. Results of the ANOVA fully replicated those of Study 1. We found a main effect of target group, $F(1,329)=5.07$, $p=.025, \eta_{\mathrm{p}}^{2}=.02$, with participants attributing more traits in general to Italians $(M=4.87, S D=0.76)$ than to immigrants $(M=4.77, S D=0.82)$, and a main effect of traits, $F(1$, $329)=70.15, p<.001, \eta_{\mathrm{p}}^{2}=.18$, with attributions of nonuniquely human traits $(M=5.01, S D=0.73)$ higher than attributions of uniquely human traits $(M=4.63, S D=0.86)$. The two main effects were qualified by a significant Target group $\times$ Traits interaction, $F(1,329)=21.43, p<.001$, $\eta_{\mathrm{p}}^{2}=.06$. Simple effects analyses showed that uniquely human traits were attributed more to Italians $(M=4.77$, $S D=0.95)$ than to immigrants $(M=4.48, S D=1.10), F(1$, $329)=22.79, p<.001, \eta_{p}^{2}=.06$, indicating outgroup infrahumanization; non-uniquely human traits were attributed equally to Italians $(M=4.96, S D=0.88)$ and immigrants $(M=5.06, S D=0.94), F(1,329)=2.74, p=.099$. Moreover, participants attributed more non-uniquely human traits than uniquely human traits both to the ingroup, $F(1,329)=10.84, p=.001, \eta_{\mathrm{p}}^{2}=.03$, and to the outgroup, $F(1,329)=73.44, p<.001, \eta_{\mathrm{p}}^{2}=.18$.

As for Study 1, a CFA (Mplus 6) was applied to the constructs measured by multiple items. In the CFA, the variables assessed by two items were measured by the respective indicators, while we applied the partial disaggregation approach to the variables assessed by at least three items (see Study 1). The model fitted the data well, $\chi^{2}(99)=171.46, p=.033, \chi^{2} / \mathrm{df}$ ratio $=1.73, \mathrm{RMSEA}=.047, \mathrm{SRMR}=.030, \mathrm{CFI}=0.98$. All parcel loadings were significant $(p s<.001)$ and higher than .75 , showing convergent validity. Moreover, all the latent variables were distinct constructs, with correlations between latent variables all different from $|1.00|$ (95\% confidence interval); thus, discriminant validity was satisfactory. 


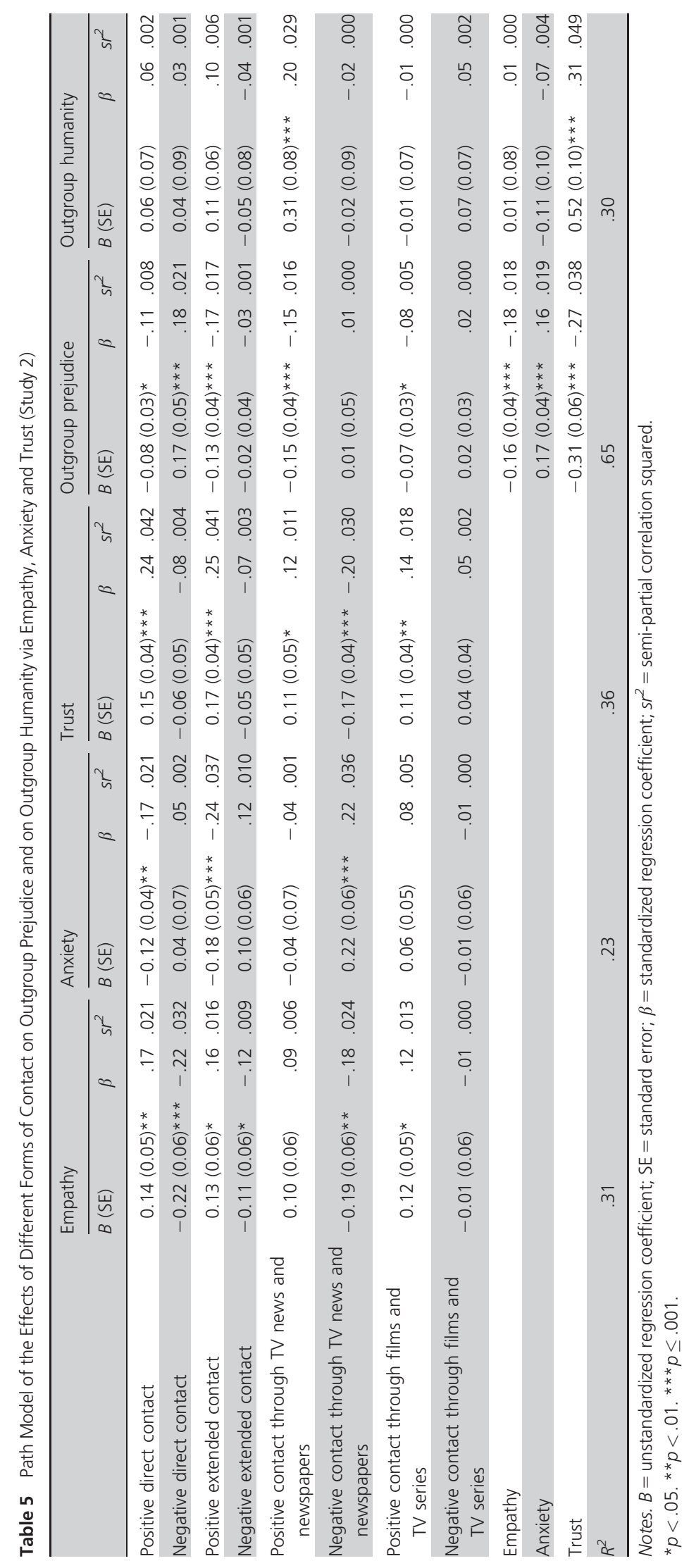




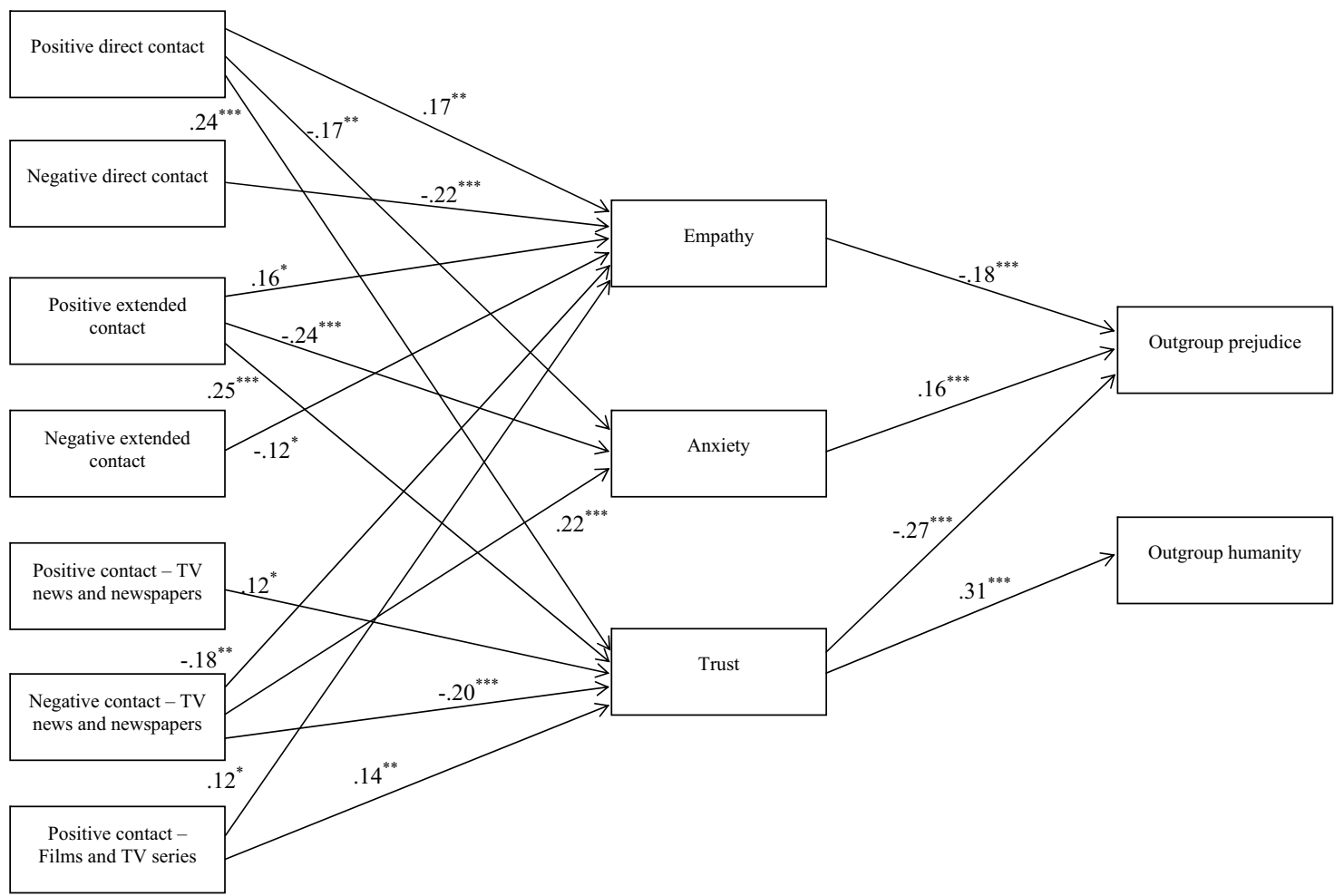

Negative contact -
Films and TV series

Figure 2 Indirect effects of different forms of contact on outgroup prejudice and on outgroup humanity via empathy, anxiety and trust (Study 2). Standardized coefficients are reported. Only significant paths are reported. Direct effects of contact variables on outgroup prejudice and on outgroup humanity are not displayed (for direct effects see Table 5). ${ }^{*} p<.05 .{ }^{*} p<.01 .{ }^{* *} p \leq .001$.

\section{Path analysis}

To assess the hypothesized relationships between variables, we tested a path model with observed variables (Mplus 6), where the eight contact indexes were entered as predictors, empathy, anxiety, and trust were the mediators, and prejudice and outgroup humanization were the outcome variables. Direct paths from the predictors to the outcome variables were estimated, as well as correlations between the predictors, between the mediators and between the outcome variables.

As shown in Table 5, positive direct contact was positively associated with empathy and trust and negatively with anxiety and prejudice; negative direct contact instead was negatively related to empathy and positively to outgroup prejudice. Regarding extended contact, the positive episodes were significantly positively associated with empathy and trust and significantly negatively associated with anxiety and prejudice, while the negative episodes were only negatively associated with empathy. Turning to mass-mediated parasocial contact, positive contact through TV news and newspapers was positively associated with trust and outgroup humanity, and negatively associated with prejudice; negative contact through TV news was instead negatively associated with empathy and trust and positively associated with intergroup anxiety. Positive contact through films was also influential, as it was significantly positively associated with empathy and trust and negatively with prejudice; negative contact through films instead revealed no significant associations. As regards relationships between mediators and outcome variables, similarly to the previous study, empathy and trust were negatively associated to, and anxiety was positively related to, prejudice. Trust was the only mediator yielding a significant positive association with outgroup humanity. All the other estimated regression coefficients were nonsignificant $(p s \geq .089)$ (see also Figure 2).

Mediation analyses. We applied bootstrapping procedures using 10,000 resamples to test significance of indirect effects. As shown in Table 6, positive direct contact had a negative indirect association with prejudice via empathy, trust, and anxiety $(p=.05)$, while negative contact had a positive indirect association with prejudice via empathy. Positive extended contact had a negative indirect 
Table 6 Unstandardized Total and Indirect Effects, and Bootstrap Point Estimates and [95\% Bootstrap Confidence Intervals] of the Effects of Different Forms of Intergroup Contact on Criterion Variables via Intergroup Emotions (Study 2)

\begin{tabular}{|c|c|c|}
\hline Mediators & Outgroup prejudice & Outgroup humanity \\
\hline Positive direct contact & $\mathrm{TE}=-0.17 * * *, \mathrm{IE}=-0.09 * * *$ & $\mathrm{TE}=0.16^{*}, \mathrm{IE}=0.09 * * *$ \\
\hline Empathy & $-0.02[-0.040,-0.003]$ & $0.00[-0.021,0.025]$ \\
\hline Trust & $-0.05[-\mathbf{0 . 0 7 7},-\mathbf{0 . 0 1 8}]$ & $0.08[0.028, \mathbf{0 . 1 3 0}]$ \\
\hline Negative direct contact & $\mathrm{TE}=0.23^{* * *}, \mathrm{IE}=0.06^{*}$ & $\mathrm{TE}=0.00, \mathrm{IE}=-0.04$ \\
\hline Empathy & $0.04[0.009,0.062]$ & $0.00[-0.038,0.033]$ \\
\hline Intergroup anxiety & $0.01[-0.017,0.032]$ & $-0.01[-0.027,0.017]$ \\
\hline Trust & $0.02[-0.014,0.053]$ & $-0.03[-0.090,0.023]$ \\
\hline Positive extended contact & $\mathrm{TE}=-0.23 * * *, \mathrm{IE}=-0.10 * * *$ & $\mathrm{TE}=0.22 * *, \mathrm{IE}=0.11 * * *$ \\
\hline Empathy & $-0.02[-\mathbf{0 . 0 4 2}, \mathbf{0 . 0 0 0}]$ & $0.00[-0.021,0.024]$ \\
\hline Intergroup anxiety & $-0.03[-\mathbf{0 . 0 5 4},-\mathbf{0 . 0 0 6}]$ & $0.02[-0.018,0.058]$ \\
\hline Trust & $-0.05[-\mathbf{0 . 0 8 3},-\mathbf{0 . 0 2 1}]$ & $0.09[0.033,0.142]$ \\
\hline Negative extended contact & $\mathrm{TE}=0.02, \mathrm{IE}=0.05^{\circ}$ & $\mathrm{TE}=-0.09, \mathrm{IE}=-0.04$ \\
\hline Intergroup anxiety & $0.02[-0.006,0.039]$ & $-0.01[-0.039,0.016]$ \\
\hline Trust & $0.02[-0.014,0.046]$ & $-0.03[-0.078,0.025]$ \\
\hline Positive contact through TV news and newspapers & $\mathrm{TE}=-0.21 * * *, \mathrm{IE}=-0.06^{*}$ & $\mathrm{TE}=0.37 * * *, \mathrm{IE}=0.06^{*}$ \\
\hline Empathy & $-0.02[-0.038,0.006]$ & $0.00[-0.017,0.019]$ \\
\hline Intergroup anxiety & $-0.01[-0.030,0.015]$ & $0.01[-0.015,0.024]$ \\
\hline Trust & $-0.04[-\mathbf{0 . 0 6 8},-\mathbf{0 . 0 0 1}]$ & $0.06[0.002,0.115]$ \\
\hline Negative contact through TV news and newspapers & $\mathrm{TE}=0.13^{*}, \mathrm{IE}=0.12^{* * *}$ & $\mathrm{TE}=-0.14, \mathrm{IE}=-0.12 * *$ \\
\hline Empathy & $0.03[0.004,0.057]$ & $0.00[-0.035,0.030]$ \\
\hline Intergroup anxiety & $0.04[0.006,0.065]$ & $-0.02[-0.070,0.023]$ \\
\hline Trust & $0.05[0.020,0.087]$ & $-0.09[-\mathbf{0 . 1 4 8 ,}-\mathbf{0 . 0 3 1}]$ \\
\hline Positive contact through films and TV series & $\mathrm{TE}=-0.11^{* *}, \mathrm{IE}=-0.04^{\circ}$ & $\mathrm{TE}=0.04, \mathrm{IE}=0.05^{\circ}$ \\
\hline Empathy & $-0.02[-0.037,0.001]$ & $0.00[-0.018,0.021]$ \\
\hline Intergroup anxiety & $0.01[-0.007,0.029]$ & $-0.01[-0.026,0.012]$ \\
\hline Trust & $-0.03[-\mathbf{0 . 0 6 0},-\mathbf{0 . 0 0 8}]$ & $0.06[0.013,0.101]$ \\
\hline Intergroup anxiety & $0.00[-0.020,0.018]$ & $0.00[-0.015,0.017]$ \\
\hline Trust & $-0.02[-0.041,0.015]$ & $0.02[-0.025,0.068]$ \\
\hline
\end{tabular}

Notes. TE $=$ Total Effect of predictor on criterion variable; IE = Indirect effect of predictor on criterion variable.

${ }^{\circ} p<.10 *{ }^{*} p<.05 .{ }^{*} p<.01 .{ }^{* * *} p \leq .001$.

Bootstrap Confidence intervals (Cls) excluding zero indicate a significant indirect effect $(p<.05)$. Bootstrap Cls with one of the limits equal to zero indicate an indirect effect significant at $p=.05$. These Cls are in bold.

association with prejudice via anxiety, trust, and empathy $(p=.05)$, while there were no significant indirect effects of negative extended contact on prejudice. Positive contact through TV news and newspapers was negatively associated with prejudice via trust, while the indirect associations of negative contact through TV news and newspapers with prejudice occurred through empathy, anxiety, and trust. As regards contact through films and TV series, only the positive episodes yielded a significant negative indirect association with prejudice via trust. Turning to the effects on outgroup humanity, the four positive forms of contact (direct, extended, through TV news and newspapers, and through films and TV series) were positively associated with outgroup humanity via trust, while among the negative forms of contact only contact through TV news and newspapers had a negative indirect association via trust.
To recap, Study 2 showed that for direct contact, extended contact, and parasocial contact through films and TV series positive episodes were more frequent than negative episodes, while the opposite occurred for parasocial contact through TV news and newspapers. Regarding the effects of contact, for direct contact and for contact through TV news and newspapers both positive and negative episodes were associated with outgroup prejudice and outgroup humanity; positive episodes were associated with reduced prejudice and more uniquely human traits attributed to outgroup members, and the opposite was found for negative episodes. For extended contact and for contact through films and TV series, only positive episodes were significantly associated with reduced prejudice and increased humanity attributions. Intergroup emotions played a mediational role between different forms of positive and negative contact and outgroup 
perceptions, i.e. prejudice and outgroup humanity. A prominent role of trust emerged, as it was the only significant mediator of contact effects on outgroup humanity, and it accounted for several of the indirect effects on outgroup prejudice.

\section{General discussion}

In two correlational studies, we examined the relationship between different forms of contact, on the one hand, and outgroup prejudice and outgroup humanity, on the other hand, in the intergroup context of Italians and immigrants in Italy. Below we discuss our findings highlighting their contribution to the existent literature on different types of intergroup contact—-direct, extended, and via mass media-the role of intergroup emotions, and their practical implications for reducing prejudice, and then we outline their limitations and propose future research directions.

\section{Direct contact}

Taken together, the results of the two studies clearly support the basic form of the intergroup contact hypothesis (Allport, 1954), confirming the beneficial impact of direct contact on evaluations and perceptions of the outgroup (Pettigrew \& Tropp, 2006). Indeed, our findings suggest that personal encounters of Italians with immigrants generally have beneficial outcomes in terms of prejudice reduction. Study 2 further demonstrated that, in line with previous findings in European and American samples (e.g., Barlow et al., 2012; Pettigrew, 2008), positive experiences of direct contact were more frequent than negative ones, although negative episodes were reported and had independent, detrimental effects on outgroup attitudes. It is noteworthy that while positive direct contact was associated with the three intergroup emotions under examination and with both prejudice and outgroup humanity, negative direct contact was related only to prejudice, partly via reduced empathy (Study 2). These findings offer an optimistic view on the strength of positive versus negative contact effects (see also Pettigrew, 2008; but cf. Barlow et al., 2012). In line with this moderate optimism, recent findings further suggest that the effects of negative contact episodes may be attenuated by the existence of positive and extensive contact in the past (Paolini et al., 2014). It is important to underline that we are not arguing that direct contact is always or naturally positive, or easy to establish. On the contrary, great care should be taken and efforts should be made by institutions to make conditions of contact situations as optimal as possible.

Furthermore, it is worth noting that the effects of direct contact were found to be significant even when indirect forms of contact were taken into account. Actually, the consistency of effects yielded by direct contact in comparison to those of indirect forms suggests that this was the most impactful form of contact (but cf. Zhou et al., 2016). Nevertheless, both extended contact and mass-mediated contact significantly contributed to predict outgroup judgments.

\section{Extended contact}

Our research confirmed the effectiveness of extended contact, showing its contribution to prejudice reduction over and beyond the effects of direct and mass-mediated contact. Moreover, results of Study 2 suggested that, similarly to direct contact, positive extended contact occurred more often than negative extended contact, and was associated with both reduced prejudice and increased outgroup humanity. This is not surprising, given that extended contact in general refers to observing friendship relations, which are usually positive. On the other hand, negative extended contact had quite weak effects, being associated with reduced empathy, but not being related to the other emotions or to prejudice and outgroup humanity. Study 2 did not find the positive association between negative extended contact and prejudice detected by Mazziotta et al. (2015). There are two main differences between our second study and research by Mazziotta et al. that might explain this discrepancy. First, in our regression model we also included mass-mediated contact that was not measured by Mazziotta and colleagues. Second, the measures of positive and negative extended contact used by Mazziotta et al. assessed the knowledge of positive and negative relationships between ingroup and outgroup members, while we also assessed the feelings of respondents when observing positive and negative extended contact. Future research should further investigate the role of positive and negative extended contact in shaping intergroup attitudes.

Taken together, our results highlight the importance of diversified social networks for mutual knowledge and prejudice reduction, and are in line with recent literature showing that contact does not operate only at the personal level, but also at the level of the social environment. In this vein, a series of studies by Christ and colleagues (2014) showed that living in areas where people have positive intergroup contact favors positive outgroup evaluations, controlling for respondents' individual level of contact. Practically, these findings also suggest that programs based on extended contact should be implemented: For example, schools could carry out interventions based on reading stories of friendship between ingroup and outgroup characters (e.g., Cameron \& Rutland, 2006; Vezzali, Stathi, Giovannini, Capozza, \& Trifiletti, 2015) or on cooperative tasks aimed at disclosing information about cross-group friendships (e.g., Vezzali, Stathi, Giovannini, Capozza, \& Visintin, 2016). 


\section{Parasocial contact through mass media}

While direct and extended contact experiences appeared to be mainly, although not exclusively, positive and yielded beneficial effects on outgroup attitudes and perceptions, the impact of mass-mediated parasocial contact was more mixed and depended both on the type of the media and on the valence of the experience.

Our research clearly indicates that, as suggested by some scholars (e.g., Pagotto et al., 2010; Sotirovic, 2001), to assess the effects of contact through mass media, it is necessary to distinguish between news media and entertainment media. Indeed, the valence of the communication is typically different in these two forms of media and thus has different effects on prejudice (Graves, 1999): The news media often convey a very negative image of immigration, while entertainment media tend to provide a more positive and personalized characterization of immigrants. Consistent with this and with previous findings (e.g., Armstrong \& Neuendorf, 1992), in Study 1 we found that contact through TV news and newspapers was associated with more prejudice (through the mediation of increased intergroup anxiety), while contact through films and TV series had a positive impact on outgroup perceptions by favoring the attribution of uniquely human traits to immigrants. Moreover, the amounts of positive and negative massmediated contact reported in Study 2, and their relations with prejudice, replicated this asymmetry, and thus supported the importance of distinguishing between different media. Indeed, our results confirm the key role of TV news and newspapers in negatively shaping people's emotions and attitudes toward immigrants (see also Geschke, Sassenberg, Ruhrmann, \& Sommer, 2010; Vaes et al., 2015). Considering that in our studies the factor that mainly contributed to maintenance of prejudice toward immigrants was the negative portrayal of immigrants in TV news and newspapers, particular attention should be paid to information conveyed by this type of media. It would be useful to propose guidelines to prevent the use of prejudicial language and to avoid the overrepresentation of illegal immigration or of immigrants in situations linked to criminality.

In addition, our findings suggest that it is especially useful to consider separately positive and negative experiences of mass-mediated contact, as they are likely to have independent effects that may be otherwise hidden (see Joyce \& Harwood, 2014; Mutz \& Goldman, 2010). In particular, results of Study 2 showed that, although Italian respondents received more often a negative image of immigrants from TV news and newspapers, and this had strong detrimental effects on their outgroup judgments, they also reported some positive contact through this type of media, and this was both directly and indirectly (i.e., via increased trust) associated with less prejudice. This finding is important because it opens up the possibility that, when positive, even news media may contribute to prejudice reduction. On the other hand, the episodes providing a positive image of immigrants in films and TV series were more frequent than the negative ones, and were associated with favorable intergroup attitudes thanks to an increase of trust toward immigrants. The negative episodes of contact through films and TV series, instead, had no significant effect on emotions and prejudice. These findings attest to the potential of entertainment media for promoting more tolerant intergroup attitudes (e.g., Bilali \& Vollhardt, 2013; Paluck, 2009; Schiappa et al., 2005), and suggest that this type of program should be incremented.

\section{The role of intergroup emotions}

Consistent with the literature (see Brown \& Hewstone, 2005), we found that the effects of direct contact on prejudice were at least partly mediated by intergroup emotions. Specifically, across both studies, we found evidence that direct contact experiences involved all three affective mediators that we considered, i.e., intergroup anxiety, empathy and trust. For extended contact, in Study 1 we found outgroup trust to be the only significant mediator, while in Study 2 intergroup anxiety and empathy also contributed to the mediated effects of positive extended contact (see also Paolini et al., 2004; Tam et al., 2009; Visintin et al., 2016). With regard to parasocial contact through mass media, the role of affective mediators was more marginal, although trust emerged again as the crucial mediator.

Notably, all the three affective mediators were associated with outgroup prejudice, while it was outgroup trust that had a major role in favoring humanity attributions to the outgroup. Intergroup trust is a complex affective state that implies positive expectations about outgroup behavior and the reduction of uncertainty in intergroup situations (e.g., Kramer \& Carnevale, 2001). This positive feeling is the basis not only for positive intergroup relations but also for perceiving outgroup members as fully human. Outgroup trust is difficult to establish but our research suggests that it could be promoted by positive experiences of direct and indirect intergroup contact and by the positive portrayal of outgroup members in the mass media. It is worth acknowledging that the prominent role of trust in respect to the other emotions under examination might be contextual: Relationships between Italians and immigrants have recently deteriorated, partly because of the increasing arrivals of immigrants in Italy and because of the economic crisis, and these phenomena have been accompanied by suspicion and distrust toward immigrants. In a context characterized by growing intergroup tensions, reestablishing mutual trust might be a necessary basis for achieving intergroup harmony (see also Kenworthy et al., 2016).

Overall, our findings have further confirmed the importance of emotional processes involved in intergroup 
experiences (Brown \& Hewstone, 2005; Pettigrew \& Tropp, 2008), and especially the key role of trust building for intergroup relations (e.g., Kenworthy et al., 2016; Tam et al., 2009).

\section{The impact of contact on prejudice and on the humanity bias}

Across both studies, the assessment of both prejudice and the humanity bias helped us to clarify the nature of attitudes and perceptions toward immigrants. In our samples, the general attitude toward immigrants was quite positive, but respondents attributed more uniquely human characteristics to Italians (the ingroup) than to immigrants (the outgroup), exhibiting an outgroup infrahumanization effect (Leyens et al., 2007). The infrahumanization phenomenon is thus confirmed in the intergroup context of Italian-immigrant relations (see also Capozza et al., 2013, Study 1), using a humanity measure different from the typical paradigm proposed by Leyens and colleagues $(2001,2007)$ based on the distinction between primary and secondary emotions. Despite the pervasiveness of this phenomenon, our research clearly indicates that infrahumanization is malleable and can be attenuated by positive experiences of direct and indirect contact with outgroup members, which lead to a more human view of the outgroup through increased trust.

\section{Limitations and future directions}

Notwithstanding the novel and replicable findings of this research, we acknowledge some limitations. First, both studies were correlational, and thus did not allow us to make definitive inferences about causality. The vast literature on intergroup contact, including both longitudinal and experimental studies (see Pettigrew \& Tropp, 2006), provides support for the causal sequence from contact to prejudice and thus we interpreted our findings accordingly. A three-wave longitudinal study (e.g., Swart et al., 2011) would be the most appropriate research methodology to test if the different forms of contact impact intergroup attitudes through the affective mediators in the way we have contended.

Another limitation is related to our samples, which were convenience samples with respondents recruited through social networks of research collaborators. It is consequently possible that data were not fully independent, i.e., some participants within the same social network might know each other, but we unfortunately cannot control this possibility. Although useful in reaching hidden or hard-to-reach populations (in this case, adult respondents rather than the usual undergraduate students), such sampling is criticized for being biased, due to its reliance on social networks and nonrandom recruitment of respondents (see Browne, 2005). However, recent research using Markov modeling to compare probability and non-probability sampling techniques found no reliable difference in terms of bias between these sampling procedures (Heckathorn, 2011). Hence, we feel any risk in using this approach is at least partly mitigated, but acknowledge that our sample was not random and may have been somewhat interdependent. Also, we cannot univocally exclude that some respondents participated to both studies, although we think it is highly unlikely that a respondent would have agreed to undertake two, quite lengthy surveys on the same topic. Furthermore, given the number of variables and the complexity of the tested regression models, it would have been more appropriate to have bigger samples. Future research should aim at replicating our findings using representative and bigger samples.

Moreover, we acknowledge some caveats of our contact measures. First, we used single items to measure extended contact (Study 1) and contact through the mass media (Studies 1 and 2). Second, the questions measuring positive and negative direct and extended contact (Study 2) investigated frequency and valence simultaneously within the same item. Thus response options might be interpreted differently by different participants. Future studies should use more precise, multiple item contact measures. Furthermore, we investigated the frequency and the valence of episodes portraying immigrants in the mass media rather than asking respondents specifically about their exposure to intergroup interactions. Given that a growing body of literature has demonstrated that mass-media exposure to positive intergroup interactions can reduce prejudice (e.g., Mazziotta et al., 2011; Ortiz \& Harwood, 2007; Schiappa et al., 2005; Shim et al., 2012), future research should aim to study the effects of the exposure to positive and negative televised cross-group interactions.

Finally, in our studies, we chose to focus on affective mediators as they have been shown to have stronger effects than cognitive mediators in the relationship between direct contact and prejudice (Pettigrew \& Tropp, 2008). However, as contended by Paolini, Hewstone, and Cairns (2007), indirect contact is likely to be more a cognitive than an affective experience, and thus may involve more cognitive mediators that should be considered in future studies.

\section{Conclusions}

To conclude, our two studies represent the first comprehensive test of the simultaneous effects of direct contact, extended contact, and parasocial contact through mass media, considering separately the impact of positive and negative episodes of these forms of contact. We showed that the forms of contact taken into account were independently related to intergroup perceptions, and emphasized the utility of distinguishing between positive and negative experiences. We further demonstrated the importance of emotional processes involved in intergroup contact experiences and pointed out the key role of trust building for intergroup relations. 
Importantly, we accounted for the effects of contact experiences on both explicit outgroup prejudice and humanity attributions to the outgroup, and thus provided support for the broad impact of contact.

Our studies suggest that, to understand the complexity of intergroup relations in a given context, it is necessary to take into account the influence of both personal experiences and vicarious experiences via the mass-media, and the emotional processes involved in contact experiences. We thus encourage future research to consider simultaneously different phenomena that can play important roles in shaping intergroup perceptions and attitudes.

\section{Acknowledgment}

This work was supported by the Foundation Cassa di Risparmio di Padova e Rovigo.

\section{References}

Aberson, C. L. (2015). Positive intergroup contact, negative intergroup contact, and threat as predictors of cognitive and affective dimensions of prejudice. Group Processes \& Intergroup Relations, 18, 743-760.

Allport, G. W. (1954). The nature of prejudice. New York, NY: Addison-Wesley.

Andrighetto, L., Mari, S., Volpato, C., \& Behluli, B. (2012). Reducing competitive victimhood in Kosovo: The role of extended contact and common ingroup identity. Political Psychology, 33, 513-529.

Armstrong, G. B., \& Neuendorf, K. A. (1992). TV Entertainment, news, and racial perceptions of college students. Journal of Communication, 42, 153-176.

Bagozzi, R. P., \& Heatherton, T. F. (1994). A general approach to representing multifaceted personality constructs: Application to state selfesteem. Structural Equation Modeling, 1, 35-67.

Bandura, A. (1999). Moral disengagement in the perpetration of inhumanities. Personality and Social Psychology Review, 3, 193-209.

Barlow, F. K., Paolini, S., Pedersen, A., Hornsey, M. J., Radke, H. R. M., Harwood, J., et al. (2012). The contact caveat: Negative contact predicts increased prejudice more than positive contact predicts reduced prejudice. Personality and Social Psychology Bulletin, 38, 1629-1643.

Batson, C. D. (1991). The altruism question: Toward a social-psychological answer. Hillsdale, NJ: Erlbaum.

Baussano, L. F. (2012). Racism and related discriminatory practices in Italy. Retrieved September 15, 2016, from ENAR Shadow Report website http:// cms.horus.be/files/99935/MediaArchive/ publications/shadow $\% 20$ report\%202010-11/14.\%20Italy.pdf

Bekhuis, H., Ruiter, S., \& Coenders, M. (2013). Xenophobia among youngsters: The effect of inter-ethnic contact. European Sociological Review, 29, 229-242.

Bilali, R., \& Vollhardt, J. R. (2013). Priming effects of a reconciliation radio drama on historical perspective-taking in the aftermath of mass violence in Rwanda. Journal of Experimental Social Psychology, 49, 144-151.

Boomgaarden, H. G., \& Vliegenthart, R. (2009). How news content influences anti-immigration attitudes: Germany, 1993-2005. European Journal of Political Research, 48, 516-542.

Brader, T., Valentino, N. A., \& Suhay, E. (2008). What triggers public opposition to immigration? Anxiety, group cues, and immigration. American Journal of Political Science, 52, 959-987.

Brown, R., Eller, A., Leeds, S., \& Stace, K. (2007). Intergroup contact and intergroup attitudes: A longitudinal study. European Journal of Social Psychology, 37, 692-703.

Brown, R., \& Hewstone, M. (2005). An integrative theory of intergroup contact. Advances in Experimental Social Psychology, 37, 255-343.

Browne, K. (2005). Snowball sampling: using social networks to research nonheterosexual women. International Journal of Social Research Methodology, 8, 47-60.

Brylka, A., Jasinskaja-Lahti, I., \& Mähönen, T. A. (2016). The majority influence on interminority attitudes: The secondary transfer effect of positive and negative contact. International Journal of Intercultural Relations, 50, 76-88.

Cameron, L., \& Rutland, A. (2006). Extended contact through story reading in school: Reducing children's prejudice toward the disabled. Journal of Social Issues, 62, 469-488.

Capozza, D., Falvo, R., Di Bernardo, G. A., Vezzali, L., \& Visintin, E. P. (2014). Intergroup contact as a strategy to improve humanity attributions: A review of studies. TPM - Testing, Psychometrics, Methodology in Applied Psychology, 21, 349-362.

Capozza, D., Trifiletti, E., Vezzali, L., \& Favara, I. (2013). Can intergroup contact improve humanity attributions? International Journal of Psychology, 48, 527-541.

Čehajić, S., Brown, J. R., \& Castano, E. (2008). Forgive and forget? Antecedents and consequences of intergroup forgiveness in Bosnia and Herzegovina. Political Psychology, 29, 351-367.

Christ, O., Hewstone, M., Tausch, N., Wagner, U., Voci, A., Hughes, J., et al. (2010). Direct contact as a moderator of extended contact effects: Cross-sectional and longitudinal impact on outgroup attitudes, behavioral intentions, and attitude certainty. Personality and Social Psychology Bulletin, 36, 1662-1674.

Christ, O., Schmid, K., Lolliot, S., Swart, H., Stolle, D., Tausch, N., et al. (2014). Contextual effect of positive intergroup contact on outgroup prejudice. Proceedings of the National Academy of Sciences of the United States of America, 111, 3996-4000.

Cuddy, A. J., Rock, M. S., \& Norton, M. I. (2007). Aid in the aftermath of hurricane Katrina: Inferences of secondary emotions and intergroup helping. Group Processes and Intergroup Relations, 10, 107-118.

Dixon, J., Durrheim, K., \& Tredoux, C. (2005). Beyond the optimal contact strategy: A reality check for the contact hypothesis. American Psychologist, 60, 697-711. 
Dovidio, J. F., Eller, A., \& Hewstone, M. (2011). Improving intergroup relations through direct, extended and other forms of in direct contact. Group Processes and Intergroup Relations, 14, 147-160.

Dovidio, J. F., \& Gaertner, S. L. (2004). Aversive racism. Advances in Experimental Social Psychology, 36, 1-51.

Durante, F. (2008). Testing and extending the Stereotype Content Model. Doctoral dissertation. Retrieved from http:// paduaresearch.cab.unipd.it/341/1/F. Durante_Dissertation.pdf

Eller, A., \& Abrams, D. (2004). Come together: Longitudinal comparisons of Pettigrew's reformulated intergroup contact model and the Common Ingroup Model in Anglo-French and MexicanAmerican contexts. European Journal of Social Psychology, 34, 229-256.

Eller, A., Abrams, D., \& Gomez, A. (2012). When the direct route is blocked: The extended contact pathway to improving intergroup relations. International Journal of Intercultural Relations, 36, 637-646.

Eurobarometer. (2008). Discrimination in the European Union: Perceptions, experiences and attitudes. Retrieved September 15, 2016, from European Commission website: http://ec.europa. eu/public_opinion/archives/ebs/ebs_ 296_en.pdf

Fullin, G., \& Reyneri, E. (2011). Low unemployment and bad jobs for new immigrants in Italy. International Migration, 49, 118-147.

Geschke, D., Sassenberg, K., Ruhrmann, G., \& Sommer, D. (2010). Effects of linguistic abstractness in the mass media: How newspaper articles shape readers' attitudes toward migrants. Journal of Media Psychology: Theories, Methods, and Applications, 22, 99-104.

Graf, S., Paolini, S., \& Rubin, M. (2014). Negative intergroup contact is more influential, but positive intergroup contact is more common: Assessing contact prominence and contact prevalence in five Central European countries. European Journal of Social Psychology, 44, 536-547.

Graves, S. B. (1999). Television and prejudice reduction: When does television as a vicarious experience make a difference? Journal of Social Issues, 55, 707-725.
Heckathorn, D. (2011). Comment: Snowball versus respondent driven sampling. Sociological Methodology, 4, 355-366.

Hooper, D., Coughlan, J., \& Mullen, M. (2008). Structural equation modelling: Guidelines for determining model fit. Electronic Journal of Business Research Methods, 6, 53-60.

Italian National Institute of Statistics (ISTAT). (2012). I migranti visti dai cittadini residenti in Italia [The image of immigrants by Italian citizens]. Retrieved September 15, 2016, from ISTAT website http://www.istat.it/it/archivio/66563

Joyce, N., \& Harwood, J. (2014). Improving intergroup attitudes through televised vicarious intergroup contact: Social cognitive processing of ingroup and outgroup information. Communication Research, 41, 627-643.

Kenworthy, J. B., Voci, A., Al Ramiah, A., Tausch, N., Hughes, J., \& Hewstone, M. (2016). Building trust in a postconflict society: An integrative model of crossgroup friendship and intergroup emotions. Journal of Conflict Resolution, 60, 1041-1070.

Kramer, R. M., \& Carnevale, P. J. (2001). Trust and intergroup negotiation. In R. Brown \& S. Gaertner (Eds.), Blackwell handbook of social psychology: Intergroup processes (pp. 431-450). Malden, MA: Blackwell.

Labianca, G., Brass, D. J., \& Gray, B. (1998). Social networks and perceptions of intergroup conflict: The role of negative relationships and third parties. Academy of Management Journal, 41, 55-67.

Lewicki, R. J., McAllister, D. J., \& Bies, R. J. (1998). Trust and distrust: New relationships and realities. Academy of Management Review, 23, 438-458.

Leyens, J. P., Demoulin, S., Vaes, J., Gaunt, R., \& Paladino, M. P. (2007). Infrahumanization: The wall of group differences. Social Issues and Policy Review, 1, 753-775.

Leyens, J. P., Rodriguez, A. P., Rodriguez, R. T., Gaunt, R., Paladino, P. M., Vaes, J., et al. (2001). Psychological essentialism and the attribution of uniquely human emotions to ingroups and outgroups. European Journal of Social Psychology, 31, 395-411.
Lienemann, B. A., \& Stopp, H. T. (2013). The association between media exposure of interracial relationships and attitudes toward interracial relationships. Journal of Applied Social Psychology, 43, E398-E415.

MacInnis, C. C., \& Hodson, G. (2012). Intergroup bias toward "Group X": Evidence of prejudice, dehumanization, avoidance, and discrimination against asexuals. Group Processes and Intergroup Relations, 15, 725-743.

Mazziotta, A., Mummendey, A., \& Wright, S. C. (2011). Vicarious intergroup contact effects: Applying social-cognitive theory to intergroup contact research. Group Processes and Intergroup Relations, 14, 255-274.

Mazziotta, A., Rohmann, A., Wright, S. C., Tezanos-Pinto, D., \& Lutterbach, S. (2015). (How) does positive and negative extended cross-group contact predict direct cross-group contact and intergroup attitudes? European Journal of Social Psychology, 45, 653-667.

Mereish, E., \& Poteat, V. P. (2015). Effects of heterosexuals' direct and extended friendships with sexual minorities on their attitudes and behaviors: Intergroup anxiety and attitude strength as mediators and moderators. Journal of Applied Social Psychology, 45, 147-157.

Miller, D. A., Smith, E. R., \& Mackie, D. M. (2004). Effects of contact and political predispositions on prejudice: Role of intergroup emotions. Group Processes and Intergroup Relations, 7, 221-237.

Monzini, P. (2005). Migration: Human rights of irregular migrants in Italy. Proceedings of the International Council on Human Rights Policy Review Meeting. Retrieved from ICHRP website: http:// www.ichrp.org/files/papers/139/122_ Monzini.pdf.

Mudu, P. (2006). Patterns of segregation in contemporary Rome. Urban Geography, $27,422-440$.

Muthén, B. O., \& Muthén, L. K. (2010). Mplus (version 6). Los Angeles, CA.

Mutz, D. C., \& Goldman, S. K. (2010). Mass media. In J. F. Dovidio, M. Hewstone, P. Glick, \& V. M. Esses (Eds.), Handbook of prejudice, stereotyping, and discrimination (pp. 241-258). London: Sage. 
O’Healy, A. (2010). Mediterranean passages: Abjection and belonging in contemporary Italian cinema. California Italian Studies Journal 1. Retrieved from University of California website http:// escholarship.org/uc/item/

2qh5d59c\#page-1.

Ortiz, M., \& Harwood, J. (2007). A social cognitive theory approach to the effect of mediated intergroup contact on intergroup attitudes. Journal of Broadcasting and Electronic Media, 51, 615-631.

Pagotto, L., \& Voci, A. (2013). Direct and mass-mediated contact: The role of different intergroup emotions. TPM - Testing, Psychometrics, Methodology in Applied Psychology, 20, 365-381.

Pagotto, L., Voci, A., \& Maculan, V. (2010). The effectiveness of intergroup contact at work: Mediators and moderators of hospital workers' prejudice towards immigrants. Journal of Community and Applied Social Psychology, 20, 317-330.

Paluck, E. L. (2009). Reducing intergroup prejudice and conflict using the media: A field experiment in Rwanda. Journal of Personality and Social Psychology, 96, 574-587.

Paolini, S., Harwood, J., Rubin, M., Husnu, S., Joyce, N., \& Hewstone, M. (2014). Positive and extensive intergroup contact in the past buffers against the disproportionate impact of negative contact in the present. European Journal of Social Psychology, 44, 548-562.

Paolini, S., Hewstone, M., \& Cairns, E. (2007). Direct and indirect intergroup friendship effects: Testing the moderating role of the affective-cognitive bases of prejudice. Personality and Social Psychology Bulletin, 33, 1406-1420.

Paolini, S., Hewstone, M., Cairns, E., \& Voci, A. (2004). Effects of direct and indirect cross-group friendships on judgments of Catholics and Protestants in Northern Ireland: The mediating role of an anxiety-reduction mechanism. Personality and Social Psychology Bulletin, 30, 770-786.

Pettigrew, T. F. (1998). Reactions towards the New Minorities of Western Europe. Annual Review of Sociology, 24, 77-103.

Pettigrew, T. F. (2008). Future directions for intergroup contact theory and research.
International Journal of Intercultural Relations, 32, 187-199.

Pettigrew, T. F., \& Tropp, L. R. (2006). A meta-analytic test of intergroup contact theory. Journal of Personality and Social Psychology, 90, 751-783.

Pettigrew, T. F., \& Tropp, L. R. (2008). How does intergroup contact reduce prejudice? Meta-analytic tests of three mediators. European Journal of Social Psychology, 38, 922-934.

Preacher, K., \& Hayes, A. F. (2008). Asymptotic and resampling strategies for assessing and comparing indirect effects in multiple mediator models. Behavior Research Methods, 40, 879-891.

Ramasubramanian, S. (2013). Intergroup contact, media exposure, and racial attitudes. Journal of Intercultural Communication Research, 42, 54-72.

Schiappa, E., Gregg, P. B., \& Hewes, D. E. (2005). The parasocial contact hypothesis. Communication Monographs, 72, 92-115.

Shim, C., Zhang, Y. B., \& Harwood, J. (2012). Direct and mediated intercultural contact: Koreans' attitudes toward US Americans. Journal of International and Intercultural Communication, 5, 169-188.

Sotirovic, M. (2001). Media use and perceptions of welfare. Journal of Communication, 51, 750-774.

Stephan, W. G. (2014). Intergroup anxiety: Theory, research, and practice. Personality and Social Psychology Review, 18, 239-255.

Stephan, W. G., \& Stephan, C. W. (1985). Intergroup anxiety. Journal of Social Issues, 41, 157-175.

Swart, H., Hewstone, M., Christ, O., \& Voci, A. (2011). Affective mediators of intergroup contact: A three-wave longitudinal study in South Africa. Journal of Personality and Social Psychology, 101, 1221-1238.

Tam, T., Hewstone, M., Kenworthy, J. B., \& Cairns, E. (2009). Intergroup trust in Northern Ireland. Personality and Social Psychology Bulletin, 35, 45-59.

ter Wal, J., D’haenens, L., \& Koeman, J. (2005). (Re)presentation of ethnicity in EU and Dutch domestic news: A quantitative analysis. Media, Culture and Society, 27, 937-950.

Turner, R. N., Hewstone, M., \& Voci, A. (2007). Reducing explicit and implicit outgroup prejudice via direct and extended contact: The mediating role of self-disclosure and intergroup anxiety. Journal of Personality and Social Psychology, 93, 369-388.

Turner, R. N., Hewstone, M., Voci, A., Paolini, S., \& Christ, O. (2007). Reducing prejudice via direct and extended crossgroup friendship. European Review of Social Psychology, 18, 212-255.

Turner, R. N., Tam, T., Hewstone, M., Kenworthy, J., \& Cairns, E. (2013). Contact between Catholic and Protestant schoolchildren in Northern Ireland. Journal of Applied Social Psychology, 43, E216-E228.

Vaes, J., Latrofa, M., Vieno, A., \& Pastore, M. (2015). Exposure to politicized media and prejudice against immigrants in Italy: Identifying its impact and psychological mediators. Psicologia Sociale, 10, 141-160.

Vaes, J., Leyens, J., Ph., Paladino, M. P., \& Pires Miranda, M. (2012). We are human, they are not: Driving forces behind outgroup dehumanisation and the humanisation of the ingroup. European Review of Social Psychology, 23, 64-106.

Vezzali, L., Hewstone, M., Capozza, D., Giovannini, D., \& Wölfer, R. (2014). Improving intergroup relations with extended and vicarious forms of indirect contact. European Review of Social Psychology, 25, 314-389.

Vezzali, L., Stathi, S., Giovannini, D., Capozza, D., \& Trifiletti, E. (2015). The greatest magic of Harry Potter: Reducing prejudice. Journal of Applied Social Psychology, 45, 105-121.

Vezzali, L., Stathi, S., Giovannini, D., Capozza, D., Visintin, E. P. (2016). “And the best essay is...": Extended contact and cross-group friendships at school. British Journal of Social Psychology, 54, 601-605.

Visintin, E. P., Brylka, A., Green, E. G. T., Mähönen, T. A., \& Jasinskaja-Lahti, I. (2016). The dynamics of interminority extended contact: The role of affective and cognitive mediators. Cultural Diversity and Ethnic Minority Psychology, 22, 467-478.

Voci, A. (2006). The link between identification and in-group favouritism: Effects 
of threat to social identity and trustrelated emotions. British Journal of Social Psychology, 45, 265-284.

Voci, A., \& Hewstone, M. (2003). Intergroup contact and prejudice toward immigrants in Italy: The mediation role of anxiety and the moderation role of group salience. Group Processes and Intergroup Relations, 6, 37-54.
Voci, A., \& Hewstone, M. (2007). L'importanza dell'empatia nella relazione tra contatto e riduzione del pregiudizio [The importance of empathy in the relationship between contact and prejudice reduction.] In R. Brown, D. Capozza, \& O. Licciardello (Eds.), Immigrazione, acculturazione, modalità di contatto (pp. 33-49). Milano, Italy: Franco Angeli.
Wright, S. C., Aron, A., McLaughlin-Volpe, T., \& Ropp, S. A. (1997). The extended contact effect: Knowledge of cross-group friendships and prejudice. Journal of Personality and Social Psychology, 73, 73-90.

Zhou, S., Page-Gould, E., Aron, A., Moyer, A., \& Hewstone, M. (2016). A metaanalysis of the extended contact hypothesis. Unpublished manuscript. 